\title{
Maternal Nutrition and Cognitive Health - Opinion
}

\author{
Lynn Cornish $\mathbf{M}^{*}$ \\ Acadian Seaplants Limited, JS Craigie Research Centre, Canada
}

Submission: July 18, 2017; Published: March 15, 2018

*Corresponding author: Lynn Cornish M, Acadian Seaplants Limited, JS Craigie Research Centre, Canada; Email: mlc@acadian.ca

Keywords: Taurine; Zinc; Magnesium; Osmoregulation; Amino-sulfonic acid; Myelination

Abbreviations: AA: Arachidonic Acid; DHA: Docosahexaenoic Acid; EPA: Eicosapentaenoic Acid; NMDA: N-methyl D-aspartate; WHO: World Health Organization

\section{Opinion}

The human brain is a precious and complex organ, responsible for all the qualities and functional characteristics that define humanity. It increases in size from 350-400g in infants to 1.3$1.4 \mathrm{~kg}$ in adults, and it is composed of ca. $78 \%$ water, $12 \%$ lipid $8 \%$ protein, and $1 \%$ carbohydrate. It is not the size of the human brain that clearly differentiates Homo sapiens from our closest living relatives, the chimpanzees, but it is its well documented structural and organizational sophistication. Considering the very earliest development of the human brain, at a time approximately 5-7 million years ago when it is theorized that H. sapiens diverged from the non-human primates, nutritional factors must have played a fundamental role. Food, after all, is defined as a substance consisting of protein, carbohydrates, and fats, used in the body of an organism to sustain growth, repair, and vital processes, and to furnish energy.

It is well recognized that a number of important nutrients are essential for brain development, and these include essential polyunsaturated fatty acids, especially arachidonic acid (AA), docosahexaenoic acid (DHA), and eicosapentaenoic acid (EPA), as well as taurine, zinc, magnesium, and iodine, among others. The fatty acid profile of the typical healthy human brain is characterized by approximately equal proportions of DHA and $\mathrm{AA}$, and their acquisition and ratio to one another is completely dependent on diet. DHA is critical for visual acuity, and it is important in activities that underlie cognitive development and in the connectivity of higher cortical pathways. Numerous studies have demonstrated critical benefits of maternal DHA and EPA supplementation regarding the protection and development of the neonatal brain. Some modern foods are enriched in DHA, but the best natural sources for DHA and AA are direct from egg yolk, some animal meat and organs, micro and macro algae, cold water fish and shellfish that directly or indirectly feed on algae.
Taurine is a phylo genetically ancient compound, a free amino-sulfonic acid, mainly acquired through diet, although it is only found in trace amounts in the plant kingdom, it is plentiful in red seaweeds, marine fish and shellfish. Taurine's neuro active properties include osmoregulation, membrane stabilization, calcium homeostasis, and neuro modulation, and the highest concentrations occur in the developing brain. Levels in adults are approximately $1 / 3$ those of neonates, highlighting the importance of this compound in maternal nutrition. Magnesium and zinc are essential brain nutrients as well, and they function in neural protection through a non-competitive channel blockade of the N-methyl D-aspartate (NMDA) receptor, thereby reducing excitotoxic neuronal damage. This process is critical for synaptic plasticity and important for the ability to store new information in neural networks.

The presence of zinc within the neuronal circuitry of the brain has been shown to link cognitive pathways, playing important roles in learning, development, and memory. It modulates intracellular and intercellular neuronal signalling and regulates cell division and proliferation. Zinc deficiencies in the brain can lead to lack of concentration, difficulties with learning and memory, loss of neurons, decreased brain volume, low infant birth rates, and cognitive abnormalities in developing neonates. of significance from a maternal nutritional perspective, zinc has a rapid turnover rate in the plasma pool, such that a daily intake of zinc is required to achieve the steady-state and to maintain and support all of its functions in the human body. Sources of dietary zinc include certain cuts of meat, shellfish, especially oysters, and seaweeds. The presence of an abundance of phytates in plant-based diets, however, can tightly bind to zinc ions, rendering them unavailable. 
Vitamin B12 is intrinsically associated with factors impacting brain development, including altered cerebral blood flow, compromised cognition control, and language function in humans. Newborn infants experiencing a diet devoid of B12 are the most susceptible to deficiencies since their body stores are utilized for tissue synthesis extensively during the first month of life. Without replenishment, this endogenous supply should last about 8 months, but if the mother is also deficient in B12, the risk to the infant includes cerebral and optic nerve atrophy, apathy and coma, hypotonia, and developmental delay. The adequacy of maternal intake and adsorption of B12 during pregnancy and lactation has a stronger influence on infant status than do maternal stores, and even relatively short-term maternal deficiencies can negatively impact infant development. Vitamin B12 is found exclusively in animal products such as meat, eggs, fish, and milk, but it has also been found in some species of sea weed.

The World Health Organization (WHO) states that iodine deficiency is the single greatest cause of preventable mental impairment in the world. This important nutrient is necessary for the synthesis of thyroid hormones which are essential for central nervous system development, including neurogenesis, neuronal migration, axon and dendrite growth, synaptogenesis, and myelination. Humans are unable to synthesize iodine, so it must be obtained from food, and the most robust natural sources are derived from the marine environment. Maternal iodine deficiency is particularly detrimental to cognitive function,

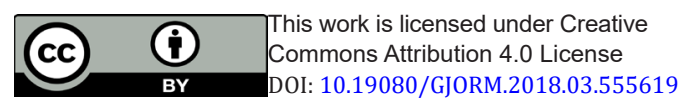

and has been repeatedly shown to have adverse effects on the neurodevelopment of offspring, even impacting IQ status and reading ability of children at 8 and 9 years of age.

While there are other brain essential nutrients as well, it is very important to recognize the role of maternal nutrition before, during, and after conception. Brain development continues up to at least 2 years of age, and a well-balanced diet rich in these nutrients is crucial for healthy physical and mental development. Theories around early Homo sapiens' unique, and perhaps serendipitous brain development, center on the likelihood of access to a shore-based diet, where fish and shellfish, seaweeds, and birds' eggs could have provided all the nutrients necessary for advancing the functional sophistication of the human brain.

The current proliferation of unhealthy foods can readily displace nutritive components in maternal diets, and this effect may be overlooked by expectant mothers, particularly those with moderate to low education levels, or who have a challenging socioeconomic status, or other issues related to demographics and, or environment. Unhealthy foods have become so entrenched in the global human psyche, that many of us are even unaware of the overall impact fueled by reams of advertising based upon subliminal seduction around foods high in sugar, salt, and fats, aimed at both children and adults. It is certainly time to accurately reassess and take advantage of the appropriate food sources for all the brain essential nutrients necessary in maternal nutrition, with the healthy development of offspring as the highest priority.

Your next submission with Juniper Publishers
will reach you the below assets
- Quality Editorial service
- Swift Peer Review
- Reprints availability
- E-prints Service
- Manuscript Podcast for convenient understanding
- Global attainment for your research
- Manuscript accessibility in different formats
( Pdf, E-pub, Full Text, Audio)
- Unceasing customer service
Track the below URL for one-step submission
https://juniperpublishers.com/online-submission.php

